\title{
Copula-Based Method for Estimating the Minimum Void Ratio Parameters of Tailings Deposits
}

\author{
Hao Li, Yichuan Tang, Shibo Li $\mathbb{D}$, Jianquan Ma $\mathbb{D}$, and Xiaojie Zhao \\ College of Geology and Environment, Xi'an University of Science and Technology, Xi'an 710054, China \\ Correspondence should be addressed to Shibo Li; lishibo@xust.edu.cn
}

Received 9 July 2021; Accepted 24 August 2021; Published 23 September 2021

Academic Editor: Zhongqiong Zhang

Copyright ( $2021 \mathrm{Hao}$ Li et al. This is an open access article distributed under the Creative Commons Attribution License, which permits unrestricted use, distribution, and reproduction in any medium, provided the original work is properly cited.

\begin{abstract}
The pore ratio is an important parameter affecting the stability and safety of tailings reservoirs; however, the relationship between the pore ratio and physical properties of tailings sand has not been researched in-depth. In this paper, using the tailings from a tungsten mine in southern Shaanxi as a case study, the correlation between the minimum void ratio and related parameters is analyzed, based on laboratory test data, and the optimal marginal distribution function of the parameters is determined. The Gumbel-Hougard copula function that best describes the correlation between parameters is identified, and it is used to establish the joint probability distribution model of the three parameters, and the guarantee rate $\alpha$ is introduced to estimate and analyze the minimum void ratio. The results show that the optimal edge distribution of the fine particle content and specific gravity follows a truncated normal distribution, and the optimal edge distribution of the minimum void ratio follows a logarithmic normal distribution. According to AIC criterion, the Gumbel-Hougard copula is the best three-dimensional copula function to fit the minimum void ratio and related parameters. When the guarantee rate $\alpha$ is 0.485 , the joint probability distribution model achieves optimal performance in terms of estimating the minimum void ratio. The maximum error of the estimation is $1.99 \%$, which is verified through data, and the estimation meets the requirements for practical engineering. The method proposed in this paper uses the existing measured data to establish a joint probability distribution model and combines the collected fine particle content and specific gravity data with the guarantee rate to estimate the minimum void ratio, providing a novel basis for the study of the physical properties of tailings.
\end{abstract}

\section{Introduction}

Tailings, as artificial accumulations of rock and soil, have certain regularity in terms of their particle size distribution [1]. In particular, the content of coarse and fine particles has a regular distribution with the length of the sedimentary beach, making tailings with different particle sizes and contents exhibit different pore characteristics and structures, which affects the consolidation degree, seepage characteristics, and the location of the infiltration line of the tailings [2]. Therefore, the accurate and simple determination of the pore characteristics has practical engineering significance for the design of tailings dams and their safe operation $[3,4]$.

Void ratio is the main parameter to describe the porosity characteristics of rock and soil in engineering. The void ratio can be obtained using a combination of in-situ field tests and laboratory tests. But the test process is complicated, and the error fluctuation range of test data is usually large. Mathematical methods such as probability and statistics make it feasible to find correlations between the minimum void ratio and related parameters using, that is facilitating the estimation of the minimum void ratio. The copula theory, proposed by Sklar [5] in 1959, is a way to construct a multiparameter correlation model, by establishing the joint distribution function. The copula theory decomposes finite-dimensional joint distributions into marginal distributions of each parameter and a copula function, which represents the correlations between parameter structures [6]. In recent years, the copula theory has been used to analyze the correlations between parameters in geotechnical engineering. Tang et al. $[7,8]$ used the copula function to characterize the influence of shear strength parameters on slope reliability and investigated the influence of sample size 
on the identification of probability models for geotechnical parameters. Zhang et al. [9, 10] introduced the advantages of using the copula function for fitting the non-normal distribution characteristics of shear strength parameters and established a Bayesian method for modelling the bivariate distribution using finite data. Zhou et al. [11] proposed an estimation method based on the copula coupling information diffusion technology, which could effectively capture the random volatility of the real distribution of parameters. Huang et al. [12] proposed the method of estimating the shear strength parameters based on the copula function [13]. However, although the copula theory has been widely used in determination of correlation between geotechnical physical parameters and permeability parameters; they do not give much in sight into the basic physical properties of rock or soil mass, especially some special rock or soil bodies, such as tailings. The stability and safety of tailing dam are closely related to the physical and mechanical properties of tailing sand, and the determination of minimum void ratio has a significant impact on the parameter analysis of consolidation degree, shear strength, and permeability of tailings [14-16]. At present, there is a lack of research on the joint probability distribution model for the minimum void ratio and related parameters, and there is no appropriate method to estimate the probability of the minimum void ratio. Therefore, there is no intuitive understanding of the permeability coefficient, consolidation coefficient, and strength parameters that affect the safety of tailings reservoirs. This makes it necessary to establish a joint probability distribution model for the minimum void ratio and related parameters to provide strong support for determining the parameters affecting the safety of tailings.

Due to the influence of tailings filling method, the particle size and content of fine particles are regularly distributed along with the length of deposition distribution. Therefore, particle size and fine particle content will affect the void ratio of sedimentary tailings and then affect the consolidation stability of tailings. In this paper, a tungsten mine tailing from Shaanxi Province, China, is selected as the experimental material, and the minimum void ratio, specific gravity, and fine grain content are selected as research parameters. Based on the measured data from laboratory tests, the joint probability distribution model for the fine content, specific gravity, and minimum void ratio of tailings sand is established combined with the copula function. The AIC and BIC criteria are used to identify the optimal edge distribution function of the minimum void ratio and related parameters. An appropriate three-dimensional copula function is selected for fitting based on the correlation between parameters, and the optimal copula function is selected by using the AIC criterion test to establish the joint probability distribution model between parameters. The minimum void ratio is estimated by combining the guarantee rate and joint distribution function, and the estimation error is analyzed. The establishment of the multivariable joint distribution function above can quickly estimate the void ratio of tailings with different particle sizes and fine particle contents and provide a reliable index range for the consolidation and seepage analysis and prediction of tailings dam.

\section{Correlations between Fine Particle Content and Minimum Void Ratio of Tailings}

2.1. Laboratory Tests. The samples were tailings from a tungsten mine in Zhen'an County, Shaanxi Province, China. Based on the particle size classification of tailing in the "Technical Code for Geotechnical Engineering of Tailings Embankment" (GB50547-2010) [17] and some research paper in tailing $[18,19]$, the experimental materials were divided into a coarse-grained group and a fine-grained group: the coarse-grained group particle sizes were 0.075 $0.1 \mathrm{~mm}, 0.1-0.15 \mathrm{~mm}, 0.15-0.25 \mathrm{~mm}, 0.25-0.3 \mathrm{~mm}, 0.3-$ $0.5 \mathrm{~mm}, 0.5-1 \mathrm{~mm}$, and $1-2 \mathrm{~mm}$. The particle size of the fine group was $0-0.075 \mathrm{~mm}$. Previous studies $[20,21]$ have found that the critical content of fine particles is $30 \%$ when controlling the properties of soil; therefore, the two groups were mixed according to eight fine particle contents: $0 \%, 30 \%$, $40 \%, 50 \%, 60 \%, 70 \%, 80 \%$, and $90 \%$, and a total of 56 groups' mixture tailing samples were obtained. The specific experimental proportions are shown in Table 1.

According to the "Technical Code for Geotechnical Engineering of Tailings Embankment" (GB50547-2010) [17] and the "Standard for Geotechnical Testing Method" (GB/T 50123-2019) [22], the calculation requirements for the minimum void ratio of tailings mud and sand are consistent with that of sand. The specific gravity $\left(G_{s}\right)$ is determined by the specific gravity bottle method, and the maximum dry density $\left(\rho_{\mathrm{dmax}}\right)$ is determined by the vibration fork method. The minimum void ratio $e_{\min }$ is obtained according to $e_{\min }=\left(G_{\mathrm{s}} / \rho_{\mathrm{dmax}}\right)-1$. The experiment and calculation results are shown in Table 2 , where the fine particle content is obtained through transformation. The specific process is as follows: the equivalent particle size of fine particles is used to replace the fine particle size, with the formula $d_{\mathrm{e}}=\left(d_{\text {up }}+\right.$ $d_{\text {down }}$ )/2 (for example, fine particle size $d_{\mathrm{e}}$ is $0.038, d_{\text {up }}$ is 0.075 , and $d_{\text {down }}=0$ ). The equivalent particle size of coarse particles is used to replace the coarse particle size, with the formula $D_{\mathrm{e}}=\left(d_{\text {up }} \times d_{\text {down }}\right)^{1 / 2}$. Assuming that the fine particle content is $a$ and the coarse particle content is $(1-a)$, the expression $g(\alpha)=d_{\mathrm{e}} \cdot a+D_{\mathrm{e}} \cdot(1-a)$ for the equivalent particle size and fine particle content is obtained. The function $f(\alpha)$ for the maximum dry density $\rho_{\mathrm{dmax}}$ and fine content $a$ was obtained by fitting the curve of the equivalent particle size and maximum dry density under different fine contents. The inverse function $f(a)$ is obtained as $m(x)=$ $f(a)^{-1}$, where $x$ is the maximum dry density and $m$ is the fine content $f_{c}$.

2.2. Determination of Parameter Correlation. In order to establish the relationship between minimum void ratio, specific gravity, and fine particle size content by using the copula function, the correlation among the three parameters should be determined first. Different copula functions describe the correlation between parameters very differently. Commonly used functions include the (1) elliptic copula function, which can simultaneously describe the positive and negative correlations between parameters, (2) the Plackett copula function, which describes the positive and 
TABLE 1: Proportioning scheme of experimental tailings.

\begin{tabular}{lcccccccccc}
\hline \multirow{2}{*}{ Skeleton particle size } & \multirow{2}{*}{ Equivalent diameter } & 0 & 30 & 40 & 50 & 60 & 70 & 80 & 90 \\
\hline $0.075-0.1$ & 0.0866 & $T_{1-0}$ & $T_{1-30}$ & $T_{1-40}$ & $T_{1-50}$ & $T_{1-60}$ & $T_{1-70}$ & $T_{1-80}$ & $T_{1-90}$ \\
$0.1-0.15$ & 0.1225 & $T_{2-0}$ & $T_{2-30}$ & $T_{2-40}$ & $T_{2-50}$ & $T_{2-60}$ & $T_{2-70}$ & $T_{2-80}$ & $T_{2-90}$ \\
$0.15-0.25$ & 0.1936 & $T_{3-0}$ & $T_{3-30}$ & $T_{3-40}$ & $T_{3-50}$ & $T_{3-60}$ & $T_{3-70}$ & $T_{3-80}$ & $T_{3-90}$ \\
$0.25-0.3$ & 0.2739 & $T_{4-0}$ & $T_{4-30}$ & $T_{4-40}$ & $T_{4-50}$ & $T_{4-60}$ & $T_{4-70}$ & $T_{4-80}$ & $T_{4-90}$ \\
$0.3-0.5$ & 0.3873 & $T_{5-0}$ & $T_{5-30}$ & $T_{5-40}$ & $T_{5-50}$ & $T_{5-60}$ & $T_{5-70}$ & $T_{5-80}$ & $T_{5-90}$ \\
$0.5-1$ & 0.7071 & $T_{6-0}$ & $T_{6-30}$ & $T_{6-40}$ & $T_{6-50}$ & $T_{6-60}$ & $T_{6-70}$ & $T_{6-80}$ & $T_{6-90}$ \\
$1-2$ & 1.4142 & $T_{7-0}$ & $T_{7-30}$ & $T_{7-40}$ & $T_{7-50}$ & $T_{7-60}$ & $T_{7-70}$ & $T_{7-80}$ & $T_{7-90}$ \\
\hline
\end{tabular}

TABLE 2: Laboratory results.

\begin{tabular}{|c|c|c|c|c|c|c|c|c|c|}
\hline Samples & $G_{\mathrm{s}}$ & $e_{\min }$ & $\rho_{\mathrm{dmax}}$ & $f_{\mathrm{c}}$ & Samples & $G_{\mathrm{s}}$ & $e_{\min }$ & $\rho_{\mathrm{dmax}}$ & $f_{\mathrm{c}}$ \\
\hline$T_{1-0}$ & 2.801 & 0.90544 & 1.47 & $87.44 \%$ & $T_{4-60}$ & 2.6084 & 0.5434 & 1.69 & $64.71 \%$ \\
\hline$T_{1-30}$ & 2.7966 & 0.69488 & 1.65 & $51.59 \%$ & $T_{4-70}$ & 2.651 & 0.60667 & 1.65 & $70.84 \%$ \\
\hline$T_{1-40}$ & 2.7262 & 0.67249 & 1.63 & $55.41 \%$ & $T_{4-80}$ & 2.6309 & 0.73082 & 1.52 & $84.98 \%$ \\
\hline$T_{1-50}$ & 2.7183 & 0.62773 & 1.67 & $60.36 \%$ & $T_{4-90}$ & 2.6761 & 0.8456 & 1.45 & $90.89 \%$ \\
\hline$T_{1-60}$ & 2.7568 & 0.68097 & 1.64 & $49.34 \%$ & $T_{5-0}$ & 2.711 & 0.81946 & 1.49 & $93.01 \%$ \\
\hline$T_{1-70}$ & 2.5778 & 0.69589 & 1.52 & $80.49 \%$ & $T_{5-30}$ & 2.7455 & 0.50853 & 1.82 & $61.65 \%$ \\
\hline$T_{1-80}$ & 2.6034 & 0.73558 & 1.5 & $83.42 \%$ & $T_{5-40}$ & 2.5548 & 0.42728 & 1.79 & $50.67 \%$ \\
\hline$T_{1-90}$ & 2.7017 & 0.83792 & 1.47 & $87.44 \%$ & $T_{5-50}$ & 2.6174 & 0.48717 & 1.76 & $61.44 \%$ \\
\hline$T_{2-0}$ & 2.79 & 0.89796 & 1.47 & $90.22 \%$ & $T_{5-60}$ & 2.6141 & 0.50237 & 1.74 & $65.59 \%$ \\
\hline$T_{2-30}$ & 2.5927 & 0.5433 & 1.68 & $52.97 \%$ & $T_{5-70}$ & 2.6378 & 0.56084 & 1.69 & $73.35 \%$ \\
\hline$T_{2-40}$ & 2.6241 & 0.59038 & 1.65 & $63.63 \%$ & $T_{5-80}$ & 2.722 & 0.65974 & 1.64 & $79.37 \%$ \\
\hline$T_{2-50}$ & 2.6356 & 0.55952 & 1.69 & $50.69 \%$ & $T_{5-90}$ & 2.7734 & 0.7553 & 1.58 & $85.39 \%$ \\
\hline$T_{2-60}$ & 2.6054 & 0.55082 & 1.68 & $52.97 \%$ & $T_{6-0}$ & 2.719 & 0.80066 & 1.51 & $89.71 \%$ \\
\hline$T_{2-70}$ & 2.5817 & 0.57421 & 1.64 & $66.02 \%$ & $T_{6-30}$ & 2.5194 & 0.45632 & 1.73 & $55.77 \%$ \\
\hline$T_{2-80}$ & 2.5679 & 0.68939 & 1.52 & $84.67 \%$ & $T_{6-40}$ & 2.563 & 0.473 & 1.74 & $48.36 \%$ \\
\hline$T_{2-90}$ & 2.691 & 0.81825 & 1.48 & $89.17 \%$ & $T_{6-50}$ & 2.6545 & 0.56146 & 1.7 & $57.11 \%$ \\
\hline$T_{3-0}$ & 2.788 & 0.90959 & 1.46 & $91.51 \%$ & $T_{6-60}$ & 2.7177 & 0.67757 & 1.62 & $75.32 \%$ \\
\hline$T_{3-30}$ & 2.7499 & 0.60815 & 1.71 & $57.96 \%$ & $T_{6-70}$ & 2.727 & 0.6527 & 1.65 & $70.04 \%$ \\
\hline$T_{3-40}$ & 2.7035 & 0.57182 & 1.72 & $49.46 \%$ & $T_{6-80}$ & 2.7494 & 0.71837 & 1.6 & $78.39 \%$ \\
\hline$T_{3-50}$ & 2.7044 & 0.60973 & 1.68 & $55.14 \%$ & $T_{6-90}$ & 2.7914 & 0.77798 & 1.57 & $82.53 \%$ \\
\hline$T_{3-60}$ & 2.6879 & 0.65919 & 1.62 & $70.72 \%$ & $T_{7-0}$ & 2.738 & 0.75513 & 1.56 & $77.95 \%$ \\
\hline$T_{3-70}$ & 2.5877 & 0.61729 & 1.6 & $74.14 \%$ & $T_{7-30}$ & 2.563 & 0.43989 & 1.78 & $43.31 \%$ \\
\hline$T_{3-80}$ & 2.6393 & 0.69184 & 1.56 & $79.99 \%$ & $T_{7-40}$ & 2.631 & 0.51207 & 1.74 & $56.47 \%$ \\
\hline$T_{3-90}$ & 2.6936 & 0.7957 & 1.5 & $87.28 \%$ & $T_{7-50}$ & 2.627 & 0.58253 & 1.66 & $59.89 \%$ \\
\hline$T_{4-0}$ & 2.738 & 0.85 & 1.48 & $88.45 \%$ & $T_{7-60}$ & 2.617 & 0.63562 & 1.6 & $71.86 \%$ \\
\hline$T_{4-30}$ & 2.7168 & 0.52627 & 1.78 & $56.10 \%$ & $T_{7-70}$ & 2.568 & 0.62532 & 1.58 & $75.02 \%$ \\
\hline$T_{4-40}$ & 2.6587 & 0.49367 & 1.78 & $46.16 \%$ & $T_{7-80}$ & 2.647 & 0.69679 & 1.56 & $77.95 \%$ \\
\hline$T_{4-50}$ & 2.6535 & 0.52498 & 1.74 & $52.54 \%$ & $T_{7-90}$ & 2.688 & 0.81622 & 1.48 & $88.02 \%$ \\
\hline
\end{tabular}

Notes: $G_{\mathrm{s}}$ denotes specific gravity; $e_{\min }$ denotes minimum void ratio; $\rho_{\mathrm{dmax}}$ denotes maximum dry density; and $f_{\mathrm{c}}$ denotes fine grain content.

negative correlations between two-dimensional parameters, and the (3) Archimedes copula function, which can only describe the positive correlation between parameters. The commonly used Pearson linear correlation coefficient $\gamma$ [23], Spearman rank correlation coefficient $\rho$ [24], and Kendall rank correlation coefficient $\tau$ [6] are selected to 
calculate the correlation between parameters. The calculation results are shown in Table 3. There is a positive correlation between $f_{\mathrm{c}}-e_{\min }, G_{\mathrm{s}}-e_{\min }$, and $f_{\mathrm{c}}-G_{\mathrm{s}}$.

\section{Copula Model and Construction}

The joint distribution function of the three-dimensional parameters constructed using the copula function primarily includes four steps:

(1) Determination of correlation coefficient between parameters, as shown in Section 2.2

(2) Determining the edge distribution function of the parameters, as shown in Section 3.1

(3) Constructing joint distribution function of parameters based on the copula theory, as shown in Section 3.2

(4) Identifying the optimal copula function, as shown in Section 3.3.

The flow chart of the process for predicting the minimum void ratio based on the copula theory is shown in Figure 1.

3.1. Edge Distribution Function Model for the Minimum Void Ratio of Tailings. In the process of constructing the copula function, the marginal distribution function of each parameter must first be determined. The joint distribution function can be constructed by combining the edge distribution function of a single parameter, and the joint distribution density function can be constructed by combining the edge density function of a single parameter and the density function of the copula function. Because the three parametersspecific gravity $\left(G_{\mathrm{s}}\right)$, fine particle content $\left(f_{\mathrm{c}}\right)$, and minimum pore ratio $\left(e_{\min }\right)$-are all positive, this study selects four distribution functions, the truncated normal distribution, logarithmic normal distribution, truncated extreme value type I, and Weibull distribution, to identify the optimal edge distribution function of the above three parameters $[1,25,26]$. Table 4 lists the probability density function and probability distribution function of the four aforementioned distributions, where $\mu$ is the mean and $\sigma$ is the standard deviation.

The optimal edge distribution function of the minimum void ratio and related parameters is identified by the AIC criterion or BIC criterion, based on measured data [27, 28]. The AIC [29] criterion and BIC [30] criterion are widely used in engineering, simple to calculate, accurate, and reliable for data fitting [13]. Their expressions are as follows:

$$
\begin{aligned}
& \mathrm{AIC}=-2 \sum_{i=1}^{N} \ln f\left(x_{i} ; p, q\right)+2 k_{1}, \\
& \mathrm{BIC}=-2 \sum_{i=1}^{N} \ln f\left(x_{i} ; p, q\right)+k_{1} \ln N
\end{aligned}
$$

TABLE 3: Correlation coefficient between parameters.

\begin{tabular}{lccc}
\hline \multirow{2}{*}{ Parameter } & \multicolumn{3}{c}{ Correlation coefficient } \\
& $\gamma$ & $\rho$ & $\tau$ \\
\hline$f \mathrm{c}-e_{\min }$ & 0.8549 & 0.8453 & 0.6788 \\
$G_{\mathrm{s}}-e_{\min }$ & 0.6203 & 0.5711 & 0.4081 \\
$f \mathrm{c}-G_{\mathrm{s}}$ & 0.3210 & 0.3026 & 0.1964 \\
\hline
\end{tabular}

Notes: $\gamma$ denotes Pearson linear correlation coefficient; $\rho$ denotes Spearman rank correlation coefficient; $\tau$ denotes Kendall rank correlation coefficient.

where $x_{i}(i=1,2, \cdots, N)$ is the measured data of the minimum void ratio and related parameters, $N$ is the number of samples, $f\left(x_{i} ; p, q\right)$ is the probability density function of the alternative edge distribution function, where $p$ and $q$ are distribution parameters, and $k_{1}$ is the number of distribution parameters for the alternative edge distribution function. Kong et al. [13] pointed out that, when the number of alternative edge distribution function parameters is the same, the optimal edge distribution function recognition results based on AIC criterion and BIC criterion are the same. Therefore, the BIC criterion is selected to identify the marginal distribution function of the minimum void ratio and related parameters. The identification results for the optimal marginal distribution function of the minimum void ratio and related parameters of coarse-fine mixed tailings with different fine contents are shown in Table 5 . It can be seen that the optimal edge distribution type in terms of fine grain content $f_{c}$ and specific gravity $G_{\mathrm{s}}$ satisfies the truncated normal distribution, and the optimal edge distribution of $e_{\min }$ satisfies the logarithmic normal distribution.

To better verify the accuracy of the BIC rule in identifying the optimal edge distribution function, Figure 2 shows the probability density function curve and nonlinear strength parameter histogram of four alternative edge distributions of fine particle content, specific gravity, and minimum void ratios. It can be seen from the graph that the optimal edge distribution type identified by BIC can accurately fit the distribution characteristics of the nonlinear strength parameters.

3.2. Constructing Joint Distribution Function. The copula function is a function that relates the joint distribution of variables and their marginal distribution, which is, in essence, also a joint distribution function. For the threedimensional case, the copula function is defined as a joint distribution function whose edge distribution is uniformly distributed in the $[0,1]^{3}$ space. According to the Sklar [5] theorem, the joint distribution function of parameters can be decomposed into two parts: the marginal distribution function of parameters and the copula function (it can be divided into two parts: (1) the correlation structure, describing the correlation between parameters, and (2) the correlation coefficient, describing the correlation between parameters). The copula function focuses on the characteristics of the marginal distribution function and correlation structure separately and can construct any required joint distribution function. The joint distribution function for the 


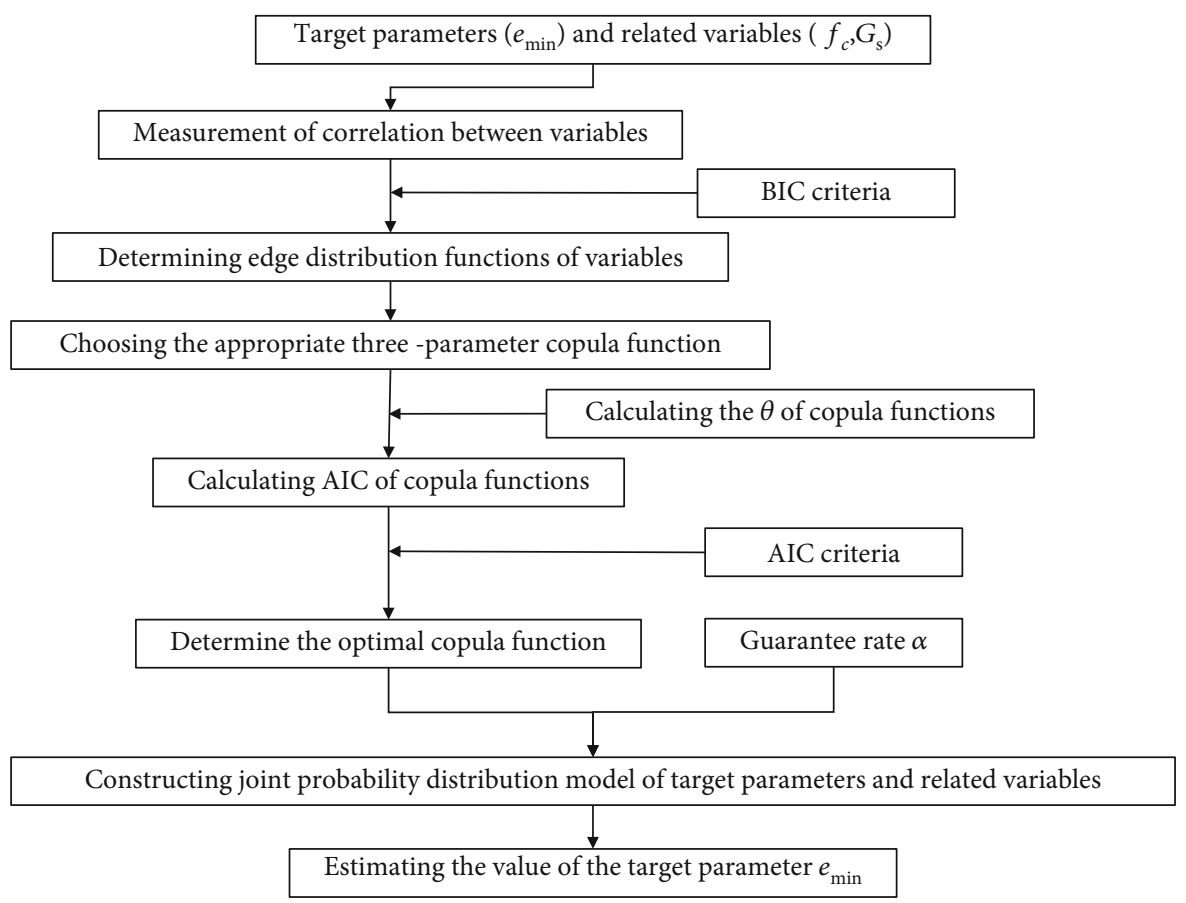

Figure 1: Flow chart of predicting minimum void ratio based on Copula theory.

minimum void ratio and related parameters constructed by the Copula function is

$$
\begin{aligned}
F\left(f_{c}, G_{s}, e_{\min }\right) & =C\left[F_{1}\left(f_{c}\right), F_{2}\left(G_{s}\right), F_{3}\left(e_{\min }\right) ; \theta\right] \\
& =C\left(u_{1}, u_{2}, u_{3} ; \theta\right),
\end{aligned}
$$

where $C$ is the copula function and $u_{1}=F_{1}(f c), u_{2}=F_{2}\left(G_{s}\right)$, and $u_{3}=F_{3}\left(e_{\min }\right)$ are the marginal distribution function of the minimum void ratio and related parameters. $\theta$ is the parameter of the copula function that characterizes the correlation between random parameters.

The joint probability density function of the minimum void ratio and related parameters is

$f\left(f_{c}, G_{s}, e_{\min }\right)=f_{1}\left(f_{c}\right) f_{2}\left(G_{s}\right) f_{3}\left(e_{\min }\right) c\left[F_{1}\left(f_{c}\right), F_{2}\left(G_{s}\right), F_{3}\left(e_{\min }\right) ; \theta\right]$.

$f_{1}\left(f_{c}\right), f_{2}\left(G_{s}\right), f_{3}\left(e_{\min }\right)$ are the edge distribution density function of the minimum void ratio and its related parameters, and $c\left[F_{1}(f c), F_{2}\left(G_{s}\right), F_{3}\left(e_{\min }\right) ; \theta\right]$ is the density function of the copula function.

It can be seen from Equations (3) and (4) that when the copula function, the marginal distribution function of the minimum void ratio and related parameters, the marginal distribution density function, and the parameter $\theta$ of the copula function are known, the joint distribution function and joint probability density function of the minimum void ratio and its related parameters can be obtained.

3.3. Constructing an Appropriate Copula Function. In Section 3.1, the marginal distribution function suitable for the three-parameter relationship is determined. And the correlation of the three parameters is also shown in Section 2.2.
Nelsen [6] proposed appropriate seven single-parameter symmetric Archimedean copula functions to describe the correlations between variables, as shown in Table 6, which can reasonably describe the positive correlation between parameters. The three-dimensional functional expression is

$$
C\left(u_{1}, u_{2}, u_{3} ; \theta\right)=\varphi^{-1}\left[\varphi\left(u_{1}\right)+\varphi\left(u_{2}\right)+\varphi\left(u_{3}\right)\right],
$$

where $\varphi\left(u_{i}\right)$ is the generator function for the Archimedean copula function. It satisfies certain properties, $\varphi(1)=0$, and $\varphi\left(u_{1}\right)+\varphi\left(u_{2}\right)+\varphi\left(u_{3}\right) \leq \varphi(0) ;$ for any $t \in[0,1], \varphi^{\prime}(t)<0$, $\varphi^{\prime \prime}(t)>0$, the generator function is a convex minus function. The Archimedean function is uniquely determined by its generator function. Different generator functions can construct different Archimedean copula functions. $\varphi^{-1}$ is the inverse function of $\varphi\left(u_{i}\right)$; and $u_{1}, u_{2}$, and $u_{3}$ are the edge distribution functions of the fine grain content $f_{c}$, specific gravity $G_{s}$, and minimum void ratio $e_{\min }$, respectively. $\theta$ is the parameter of the copula function, and its estimated value is generally obtained using the maximum likelihood estimation method, shown in the following equations:

$$
\begin{aligned}
L(\theta) & =\sum_{i=1}^{n} \ln c\left(u_{1 i}, u_{2 i}, u_{3 i} ; \theta\right), \\
c\left(u_{1}, u_{2}, u_{3}\right) & =\frac{\partial^{3} C\left(u_{1}, u_{2}, u_{3}\right)}{\partial u_{1} \partial u_{2} \partial u_{3}}, \\
\hat{\theta} & =\left.\theta\right|_{L=L_{\max }},
\end{aligned}
$$




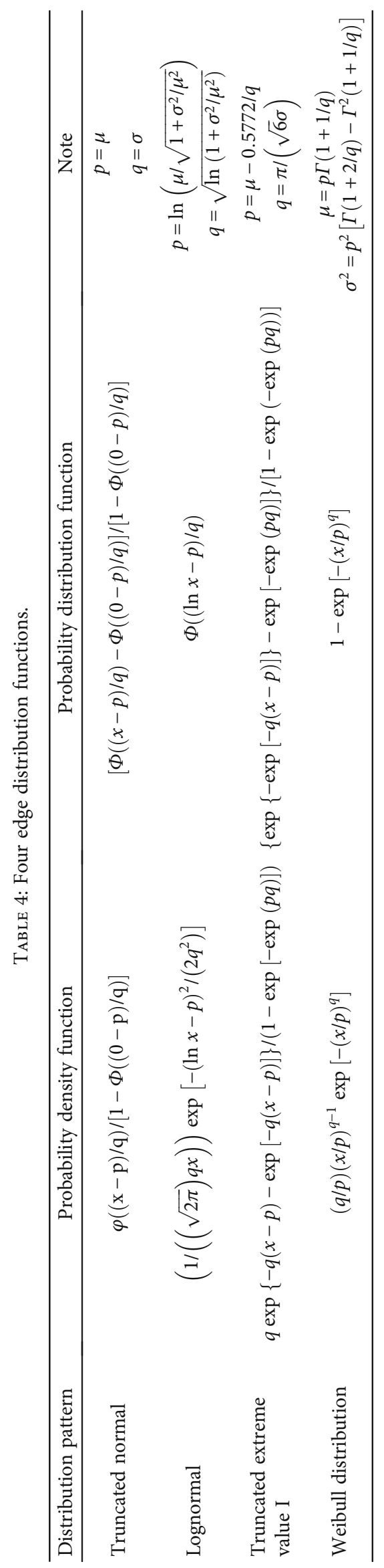


TABle 5: Parameter optimal edge distribution function recognition.

\begin{tabular}{lccccccccc}
\hline Parameter & $\begin{array}{c}\text { Number of } \\
\text { samples }\end{array}$ & $\begin{array}{c}\text { Mean } \\
\text { value }\end{array}$ & $\begin{array}{c}\text { Standard } \\
\text { deviation }\end{array}$ & $\begin{array}{c}\text { Identification } \\
\text { type }\end{array}$ & $\begin{array}{c}\text { Truncated } \\
\text { normal }\end{array}$ & Lognormal & $\begin{array}{c}\text { Truncated } \\
\text { extreme value I }\end{array}$ & $\begin{array}{c}\text { Weibull } \\
\text { distribution }\end{array}$ & $\begin{array}{c}\text { Optimal edge } \\
\text { distribution type }\end{array}$ \\
\hline$f_{\mathrm{c}}$ & 56 & 0.697 & 0.148 & BIC & -39.759 & -38.507 & -33.727 & -32.734 & Truncated normal \\
$G_{\mathrm{s}}$ & 56 & 2.671 & 0.072 & BIC & -119.983 & -119.973 & -111.379 & -107.975 & Truncated normal \\
$e_{\text {min }}$ & 56 & 0.653 & 0.128 & BIC & -56.641 & -58.068 & -55.084 & -46.196 & Lognormal \\
\hline
\end{tabular}

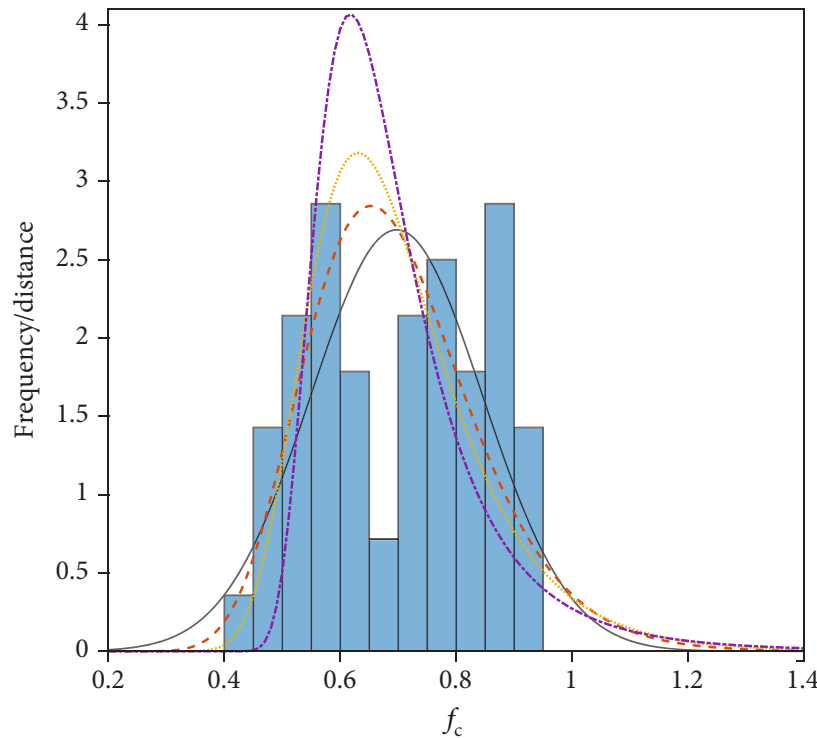

Frequency histogram Truncated normal - . . Lognormal

(a)

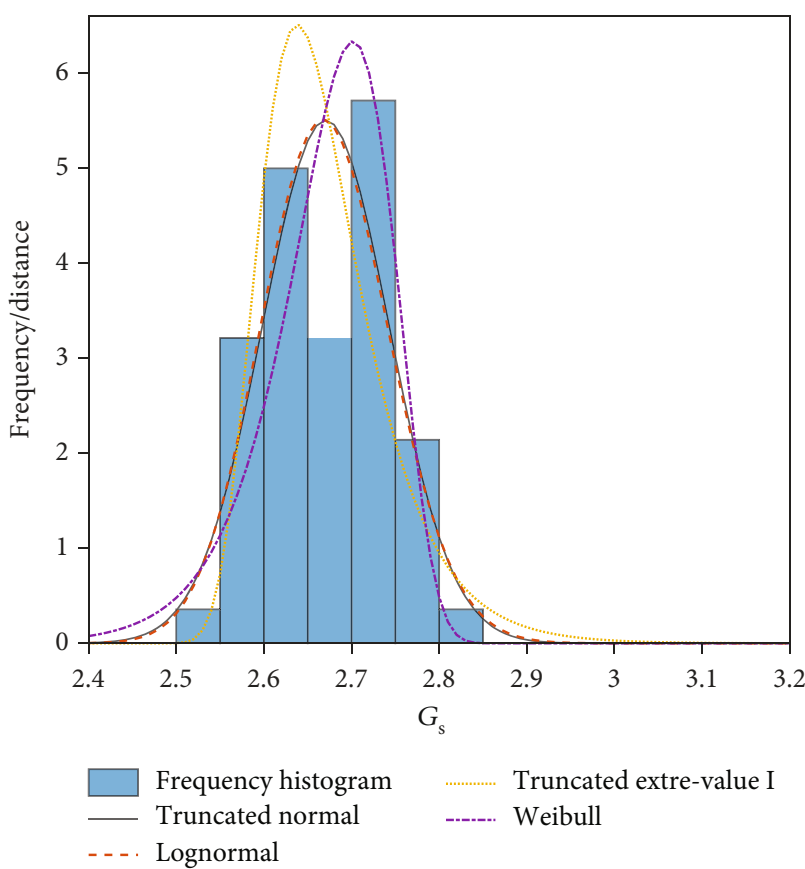

(b)

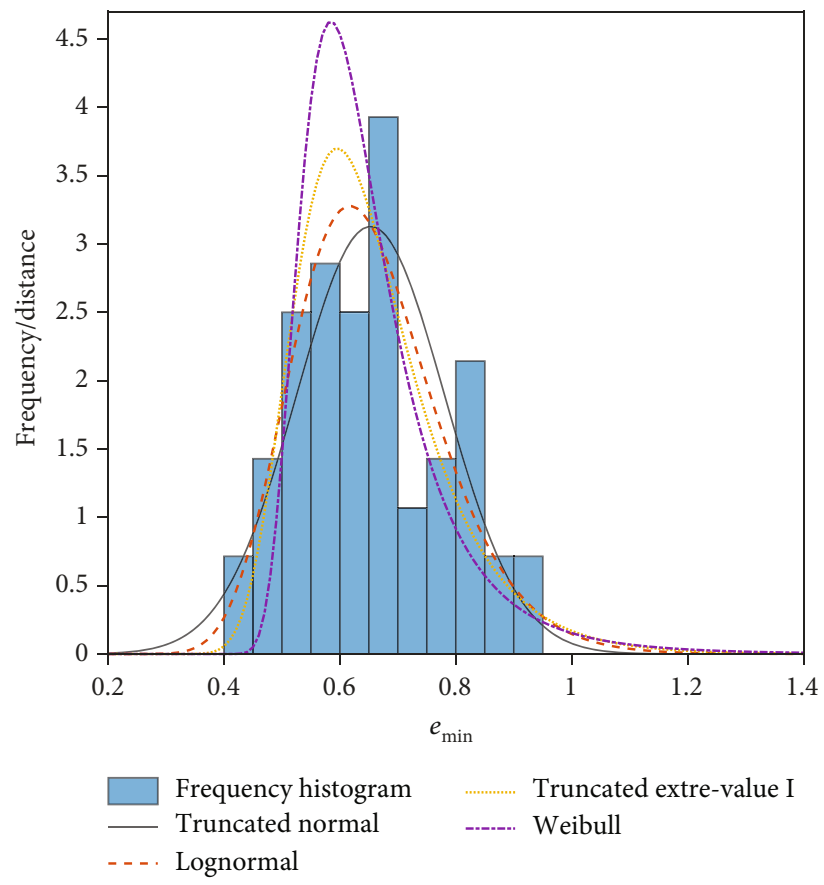

(c)

FIGURE 2: Frequency histogram of the minimum void ratio and related parameters. (a) Fine content. (b) Specific gravity. (c) Minimum void ratio. 


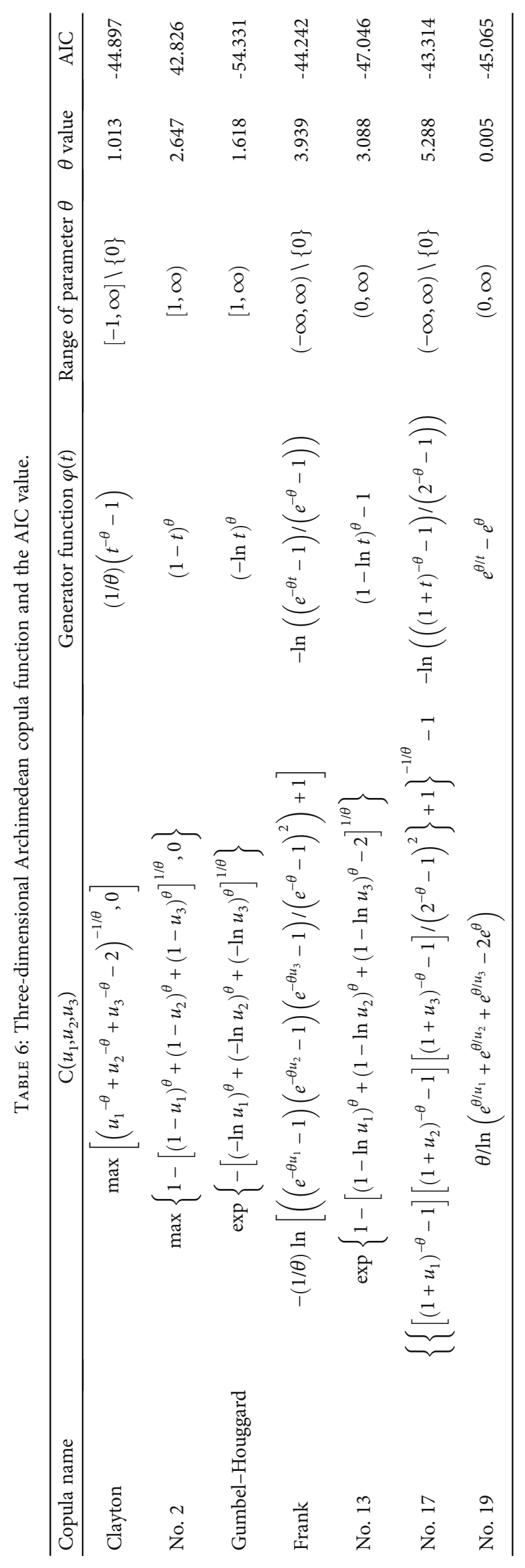




$$
\begin{aligned}
& u_{1 i}=\frac{\operatorname{rank}\left(x_{1 i}\right)}{n+1}, \\
& u_{2 i}=\frac{\operatorname{rank}\left(x_{2 i}\right)}{n+1}, \\
& u_{3 i}=\frac{\operatorname{rank}\left(x_{3 i}\right)}{n+1}, i=1,2, . ., n,
\end{aligned}
$$

where $n$ is the sample observation number; $u_{1 i}, u_{2 i}$, and $u_{3 i}$ are the empirical distribution values of the sample observation value of fine grain content $f_{c}$, specific gravity $G_{s}$, and minimum void ratio $e_{\min }$, respectively, calculated using Equation (9); and rank is the sorting function, where rank $\left(x_{i}\right)$ represents the position of $x_{i}$ in the entire series of observation data in ascending order. $c$ is the density function of $C\left(u_{1}, u_{2}, u_{3}\right)$, where $u_{1}, u_{2}$, and $u_{3}$ are the edge distribution functions of each parameter; $L$ is the logarithmic likelihood function; and $L_{\max }$ is the maximum value obtained by the $L$ function.

The goodness-of-fit of the seven selected copula functions is tested, and the copula function with the highest goodness-of-fit is selected as the optimal copula function. According to the AIC criterion, the calculation formula is

$$
A I C=-2 \sum_{i=1}^{n} \ln c\left(u_{1 i}, u_{2 i}, u_{3 i} ; \theta\right)+2 k_{2}
$$

where $C\left(u_{1}, u_{2}, u_{3} ; \theta\right)$ is the density function of the copula function and $k_{2}$ is the number of parameters of the copula function.

Using Equation (10), the AIC value of the alternative copula function is calculated, the results of which are shown in Table 6, indicating that the joint distribution model established by the Gumbel-Hougard copula function has the minimum AIC value. The $\theta$ value estimated by Equations (6)-(8) is substituted into the Gumbel-Hougard function, that is, the optimal copula function to describe the fine grain content $f_{\mathrm{c}}$, specific gravity $G_{\mathrm{s}}$, and the minimum void ratio $e_{\min }$ is

$$
\begin{aligned}
C(u 1, u 2, u 3)= & \exp \left\{-\left[\left(-\ln u_{1}\right)^{1.618}+\left(-\ln u_{2}\right)^{1.618}\right.\right. \\
& \left.\left.+\left(-\ln u_{3}\right)^{1.618}\right]^{1 / 1.618}\right\} .
\end{aligned}
$$

\section{Estimating Minimum Void Ratio Using the Copula Method}

The sedimentary environment of the tailings makes their particle size, particle size content, and pore ratio change significantly in different regions within the tailings accumulation area, which makes it difficult to estimate the relationship between the pore ratio and particle size distribution in these regions [31, 32]. The joint probability distribution model of the fine particle content, specific gravity, and minimum pore ratio is established to predict the minimum pore ratio of tailings with different particle sizes and fine particle contents [33].

The minimum pore ratio of tailings is the densest state that describes the accumulation of tailings. Therefore, the measured minimum pore ratio can easily be greater than or equal to the minimum pore ratio estimation' $e_{\min }$ [34]. The probability of the actual observation value being greater than or equal to ${ }^{\prime} e_{\min }$ is defined as the guarantee rate $\alpha$ $[35,36](0 \leq \alpha \leq 1)$, as follows:

$$
F\left(e_{\min }\right)=P\left(e_{\min } \geq e_{\min }\right)=\alpha
$$

In the case of known fine particle content $f_{\mathrm{c}}$ and specific gravity $G_{s}$, by Equation (11), the copula function of the minimum void ratio and related parameters are established, and the guarantee rate $\alpha$ is as follows:

$$
\begin{aligned}
\alpha & =F\left(e_{\min } \mid \mathrm{f}_{\mathrm{c}}=\mathrm{f}_{\mathrm{c} 0}, G_{s}=G_{s 0}\right) \\
& =P\left(e_{\min } \geq e_{\min } \mid \mathrm{f}_{\mathrm{c}}=\mathrm{f}_{\mathrm{c} 0}, G_{s}=G_{s 0}\right) \\
& =\frac{\left(\partial^{2} / \partial \mathrm{f}_{\mathrm{c} 0} \partial G_{s}\right) F\left(\mathrm{f}_{\mathrm{c} 0}, G_{s 0}^{\prime}, e_{\min }\right)}{f_{e_{\min }, \mathrm{f}_{\mathrm{c} 0}, G_{s}}\left(\mathrm{f}_{\mathrm{c} 0}, G_{s 0}{ }^{\prime}, e_{\min }\right)} \\
& =C\left(u_{3} \geq u_{03} \mid u_{1} \leq u_{01}, u_{2} \leq u_{02}\right) \\
& =\frac{\left(\partial^{2} / \partial u_{1} \partial u_{2}\right) C\left(u_{01}, u_{02}, u_{03}\right)}{\left(\partial^{2} / \partial u_{1} \partial u_{2}\right) C\left(u_{01}, u_{02}\right)} .
\end{aligned}
$$

The minimum void ratio' $e_{\min }$ can be obtained when the guarantee rate $\alpha$ is certain, and different $\alpha$ values correspond to different minimum void ratios $e_{\min }$. Therefore, there is an optimal $\alpha$ value that makes the estimation of the minimum void ratio' $e_{\min }$ fit the actual experimental results. In engineering, the correlation coefficient $r$ is often selected to measure the fitting degree of the function. The larger the value of $r(0 \leq r \leq 1)$, the higher the fitting degree, and the better the fitting effect. The formula for $r$ is shown in the following equation:

$$
r=\sqrt{1-\frac{\sum_{i=1}^{n}\left(e_{\min i}-e_{\min 0 i}\right)^{2}}{\sum_{i=1}^{n}\left(e_{\min i}-\overline{e_{\min }}\right)^{2}}} .
$$

Using Equations (13) and (14), the joint distribution model of the minimum void ratio and related parameters is established based on the 56 groups of data from the laboratory test. The estimation and correlation coefficient $r$ of the minimum void ratio $e_{\min }$ under different $\alpha$ values is calculated, and the predicted value of the minimum void ratio $e_{\min }$ is compared with the converted value from laboratory data, the data value under partial guarantee rate as shown in Table 7 (a negative value indicates that the predicted value is greater than the actual value, and a positive value indicates that the predicted value is less than the actual value). In the range of the $\alpha$ value $(0 \leq \alpha \leq 1)$, when the $r$ value is the maximum $r_{\max }$, the corresponding $\alpha$ 
TABLE 7: Comparison of the predicted and actual values of different assurance rates.

\begin{tabular}{|c|c|c|c|c|c|c|c|}
\hline Tailings sand samples & $\begin{array}{l}\text { Minimum void } \\
\text { ratio } e_{\min }\end{array}$ & $\begin{array}{c}0.285 \text { predicted } \\
\text { value' } e_{\min }\end{array}$ & Error & $\begin{array}{c}0.485 \text { predicted } \\
\text { value }^{\prime} e_{\min }\end{array}$ & Error & $\begin{array}{c}0.685 \text { predicted } \\
\text { value' } e_{\min }\end{array}$ & Error \\
\hline$T_{1-0}$ & 0.90544 & 0.8226 & $9.15 \%$ & 0.8746 & $3.41 \%$ & 0.9163 & $-1.20 \%$ \\
\hline$T_{1-30}$ & 0.69488 & 0.5357 & $22.91 \%$ & 0.5889 & $15.25 \%$ & 0.3116 & $55.16 \%$ \\
\hline$T_{1-40}$ & 0.67249 & 0.5507 & $18.11 \%$ & 0.6043 & $10.14 \%$ & 0.6617 & $1.60 \%$ \\
\hline$T_{1-50}$ & 0.62773 & 0.5737 & $8.61 \%$ & 0.6279 & $-0.03 \%$ & 0.6838 & $-8.93 \%$ \\
\hline$T_{1-60}$ & 0.68097 & 0.5263 & $22.71 \%$ & 0.5793 & $14.93 \%$ & 0.6404 & $5.96 \%$ \\
\hline$T_{1-70}$ & 0.69589 & 0.5307 & $23.74 \%$ & 0.5838 & $16.11 \%$ & 0.6404 & $7.97 \%$ \\
\hline$T_{1-80}$ & 0.73558 & 0.554 & $24.69 \%$ & 0.6076 & $17.40 \%$ & 0.6649 & $9.61 \%$ \\
\hline$T_{1-90}$ & 0.83792 & 0.6889 & $17.78 \%$ & 0.7443 & $11.17 \%$ & 0.7998 & $4.55 \%$ \\
\hline$T_{2-0}$ & 0.89796 & 0.8461 & $5.78 \%$ & 0.8972 & $0.08 \%$ & 0.9476 & $-5.53 \%$ \\
\hline$T_{2-30}$ & 0.5433 & 0.5098 & $6.17 \%$ & 0.5625 & $-3.53 \%$ & 0.6199 & $-14.10 \%$ \\
\hline$T_{2-40}$ & 0.59038 & 0.5493 & $6.96 \%$ & 0.6029 & $-2.12 \%$ & 0.6599 & $-11.78 \%$ \\
\hline$T_{2-50}$ & 0.55952 & 0.5184 & $7.35 \%$ & 0.5712 & $-2.09 \%$ & 0.6293 & $-12.47 \%$ \\
\hline$T_{2-60}$ & 0.55082 & 0.5148 & $6.54 \%$ & 0.5676 & $-3.05 \%$ & 0.625 & $-13.47 \%$ \\
\hline$T_{2-70}$ & 0.57421 & 0.525 & $8.57 \%$ & 0.578 & $-0.66 \%$ & 0.636 & $-10.76 \%$ \\
\hline$T_{2-80}$ & 0.68939 & 0.5236 & $24.05 \%$ & 0.5765 & $16.38 \%$ & 0.6338 & $8.06 \%$ \\
\hline$T_{2-90}$ & 0.81825 & 0.6721 & $17.86 \%$ & 0.7277 & $11.07 \%$ & 0.7833 & $4.27 \%$ \\
\hline$T_{3-0}$ & 0.90959 & 0.8563 & $5.86 \%$ & 0.9071 & $0.27 \%$ & 0.9569 & $-5.20 \%$ \\
\hline$T_{3-30}$ & 0.60815 & 0.5643 & $7.21 \%$ & 0.6182 & $-1.65 \%$ & 0.6752 & $-11.03 \%$ \\
\hline$T_{3-40}$ & 0.57182 & 0.5247 & $8.24 \%$ & 0.5777 & $-1.03 \%$ & 0.6349 & $-11.03 \%$ \\
\hline$T_{3-50}$ & 0.60973 & 0.5475 & $10.21 \%$ & 0.601 & $1.43 \%$ & 0.6582 & $-7.95 \%$ \\
\hline$T_{3-60}$ & 0.65919 & 0.6156 & $6.61 \%$ & 0.6707 & $-1.75 \%$ & 0.7114 & $-7.92 \%$ \\
\hline$T_{3-70}$ & 0.61729 & 0.5362 & $13.14 \%$ & 0.5895 & $4.50 \%$ & 0.6467 & $-4.76 \%$ \\
\hline$T_{3-80}$ & 0.69184 & 0.5899 & $14.73 \%$ & 0.6444 & $6.86 \%$ & 0.7013 & $-1.37 \%$ \\
\hline$T_{3-90}$ & 0.7957 & 0.6744 & $15.24 \%$ & 0.7299 & $8.27 \%$ & 0.7854 & $1.29 \%$ \\
\hline$T_{4-0}$ & 0.85 & 0.758 & $10.82 \%$ & 0.8121 & $4.46 \%$ & 0.8647 & $-1.73 \%$ \\
\hline$T_{4-30}$ & 0.52627 & 0.5531 & $-5.10 \%$ & 0.6067 & $-15.28 \%$ & 0.6638 & $-26.13 \%$ \\
\hline$T_{4-40}$ & 0.49367 & 0.5088 & $-3.06 \%$ & 0.5615 & $-13.74 \%$ & 0.6188 & $-25.35 \%$ \\
\hline$T_{4-50}$ & 0.52498 & 0.5286 & $-0.69 \%$ & 0.5817 & $-10.80 \%$ & 0.6389 & $-21.70 \%$ \\
\hline$T_{4-60}$ & 0.5434 & 0.5412 & $0.40 \%$ & 0.5946 & $-9.42 \%$ & 0.6517 & $-19.93 \%$ \\
\hline$T_{4-70}$ & 0.60667 & 0.5866 & $3.31 \%$ & 0.641 & $-5.66 \%$ & 0.6979 & $-15.04 \%$ \\
\hline$T_{4-80}$ & 0.73082 & 0.5833 & $20.19 \%$ & 0.6377 & $12.74 \%$ & 0.6945 & $4.97 \%$ \\
\hline$T_{4-90}$ & 0.8456 & 0.648 & $23.37 \%$ & 0.7035 & $16.80 \%$ & 0.7596 & $10.17 \%$ \\
\hline$T_{5-0}$ & 0.81946 & 0.7136 & $12.92 \%$ & 0.7687 & $6.19 \%$ & 0.8232 & $-0.46 \%$ \\
\hline$T_{5-30}$ & 0.50853 & 0.5836 & $-14.76 \%$ & 0.638 & $-25.46 \%$ & 0.6949 & $-36.65 \%$ \\
\hline$T_{5-40}$ & 0.42728 & 0.4902 & $-14.73 \%$ & 0.5426 & $-26.99 \%$ & 0.6002 & $-40.47 \%$ \\
\hline$T_{5-50}$ & 0.48717 & 0.5403 & $-10.91 \%$ & 0.5936 & $-21.85 \%$ & 0.6508 & $-33.59 \%$ \\
\hline$T_{5-60}$ & 0.50237 & 0.5467 & $-8.82 \%$ & 0.6002 & $-19.47 \%$ & 0.6574 & $-30.86 \%$ \\
\hline$T_{5-70}$ & 0.56084 & 0.5798 & $-3.38 \%$ & 0.6341 & $-13.06 \%$ & 0.691 & $-23.21 \%$ \\
\hline$T_{5-80}$ & 0.65974 & 0.6896 & $-4.53 \%$ & 0.745 & $-12.92 \%$ & 0.8002 & $-21.29 \%$ \\
\hline$T_{5-90}$ & 0.7553 & 0.7842 & $-3.83 \%$ & 0.8375 & $-10.88 \%$ & 0.8897 & $-17.79 \%$ \\
\hline$T_{6-0}$ & 0.80066 & 0.7252 & $9.42 \%$ & 0.7802 & $2.56 \%$ & 0.8343 & $-4.20 \%$ \\
\hline$T_{6-30}$ & 0.45632 & 0.4803 & $-5.26 \%$ & 0.5325 & $-16.69 \%$ & 0.5903 & $-29.36 \%$ \\
\hline
\end{tabular}


TABLE 7: Continued.

\begin{tabular}{|c|c|c|c|c|c|c|c|}
\hline Tailings sand samples & $\begin{array}{l}\text { Minimum void } \\
\text { ratio } e_{\min }\end{array}$ & $\begin{array}{c}0.285 \text { predicted } \\
\text { value }^{\prime} e_{\min }\end{array}$ & Error & $\begin{array}{c}0.485 \text { predicted } \\
\text { value }^{\prime} e_{\min }\end{array}$ & Error & $\begin{array}{c}0.685 \text { predicted } \\
\text { value }^{\prime} e_{\min }\end{array}$ & Error \\
\hline$T_{6-40}$ & 0.473 & 0.4897 & $-3.53 \%$ & 0.542 & $-14.59 \%$ & 0.5996 & $-26.77 \%$ \\
\hline$T_{6-50}$ & 0.56146 & 0.5445 & $3.02 \%$ & 0.598 & $-6.51 \%$ & 0.6551 & $-16.68 \%$ \\
\hline$T_{6-60}$ & 0.67757 & 0.6615 & $2.37 \%$ & 0.7171 & $-5.83 \%$ & 0.773 & $-14.08 \%$ \\
\hline$T_{6-70}$ & 0.6527 & 0.6323 & $3.13 \%$ & 0.6877 & $-5.36 \%$ & 0.744 & $-13.99 \%$ \\
\hline$T_{6-80}$ & 0.71837 & 0.7049 & $1.88 \%$ & 0.7601 & $-5.81 \%$ & 0.8149 & $-13.44 \%$ \\
\hline$T_{6-90}$ & 0.77798 & 0.763 & $1.93 \%$ & 0.817 & $-5.02 \%$ & 0.8698 & $-11.80 \%$ \\
\hline$T_{7-0}$ & 0.75513 & 0.6942 & $8.07 \%$ & 0.7496 & $0.73 \%$ & 0.8046 & $-6.55 \%$ \\
\hline$T_{7-30}$ & 0.43989 & 0.4806 & $-9.25 \%$ & 0.5329 & $-21.14 \%$ & 0.5906 & $-34.26 \%$ \\
\hline$T_{7-40}$ & 0.51207 & 0.534 & $-4.28 \%$ & 0.5872 & $-14.67 \%$ & 0.6443 & $-25.82 \%$ \\
\hline$T_{7-50}$ & 0.58253 & 0.5416 & $7.03 \%$ & 0.595 & $-2.14 \%$ & 0.6521 & $-11.94 \%$ \\
\hline$T_{7-60}$ & 0.63562 & 0.5588 & $12.09 \%$ & 0.6126 & $3.62 \%$ & 0.6696 & $-5.35 \%$ \\
\hline$T_{7-70}$ & 0.62532 & 0.5215 & $16.60 \%$ & 0.5744 & $8.14 \%$ & 0.6317 & $-1.02 \%$ \\
\hline$T_{7-80}$ & 0.69679 & 0.5964 & $14.41 \%$ & 0.651 & $6.57 \%$ & 0.7078 & $-1.58 \%$ \\
\hline$T_{7-90}$ & 0.81622 & 0.6658 & $18.43 \%$ & 0.7213 & $11.63 \%$ & 0.7771 & $4.79 \%$ \\
\hline
\end{tabular}

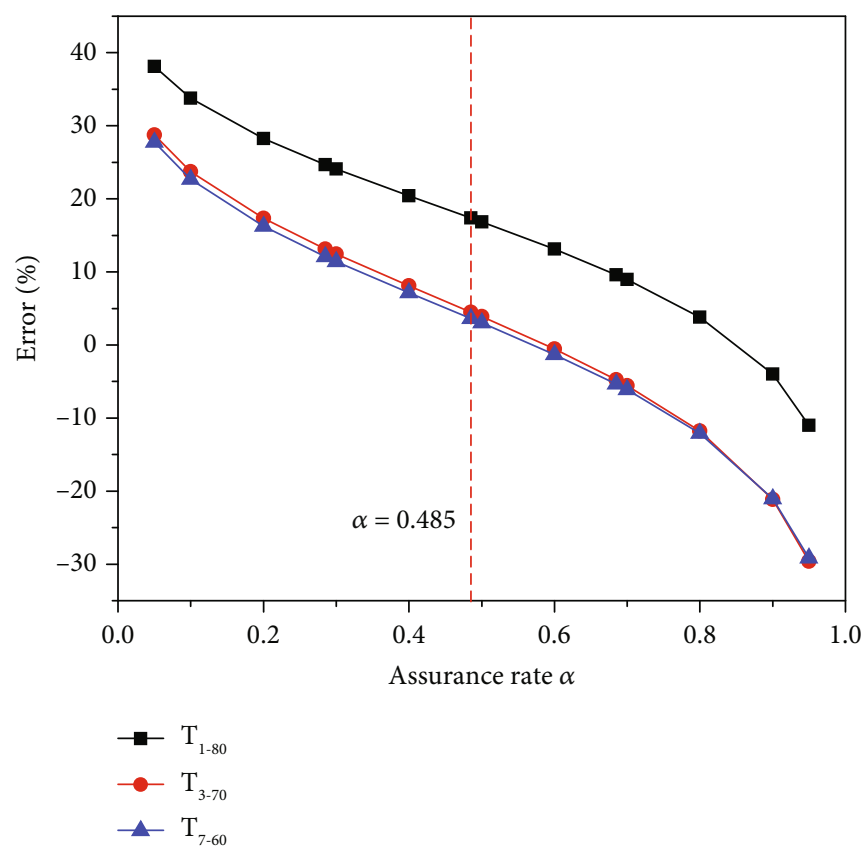

Figure 3: Valuation error curves under different guarantee rates.

value is the Gumbel-Hougard copula function (Equation (11)). Calculations show that, when $\alpha=0.485$, the maximum value of $r$ is 0.8403 . The Gumbel-Hougard copula selected in this paper can achieve an optimal fitting guarantee rate $\alpha_{0}$ of 0.485 . We randomly selected three sets of data $\left(T_{1-80}, T_{3-70}\right.$, and $T_{7-60}$ ) to draw a "guarantee rate-error curve" (Figure 3); it can be seen from Figure 3 and Table 7 that, when the guarantee rate $\alpha=\alpha_{0}$, the error between the estimation of the minimum void ratio and the measured value is the smallest, and the estimation effect is the best. When $\alpha>\alpha_{0}$, with increases in $\alpha$, the predicted value of the minimum void ratio becomes larger and larger. The greater the probability of the predicted value being greater than the measured value, the worse the estimation. When $\alpha<\alpha_{0}$, with decreases in $\alpha$, the predicted value of the minimum void ratio becomes smaller and smaller. The greater the probability that the predicted value is less than the measured value, the worse the estimation effect.

Using the Gumbel-Hougard copula function with the best correlation between the description specific gravity, fine 
TABLE 8: Forecasted data results.

\begin{tabular}{|c|c|c|c|c|c|c|}
\hline Tailings sand samples & $\begin{array}{l}\text { Maximum dry density } \\
\rho_{\mathrm{d} \max }\end{array}$ & $\begin{array}{c}\text { Fine grain content } \\
f_{\mathrm{c}}\end{array}$ & $\begin{array}{l}\text { Specific gravity } \\
\qquad G_{\mathrm{s}}\end{array}$ & $\begin{array}{l}\text { Minimum void ratio } \\
e_{\min }\end{array}$ & $\begin{array}{c}\text { Prediction of } \\
\text { minimum void ratio } \\
{ }^{\prime} e_{\min }\end{array}$ & Error \\
\hline \multirow{6}{*}{$\begin{array}{l}\text { Fine } 0.25-0.3 \\
\text { Skeleton } 1-2\end{array}$} & 1.56 & $74.69 \%$ & 2.738 & 0.75513 & 0.7252 & $1.50 \%$ \\
\hline & 1.71 & $53.94 \%$ & 2.757 & 0.61228 & 0.5989 & $0.67 \%$ \\
\hline & 1.73 & $48.57 \%$ & 2.657 & 0.53584 & 0.569 & $-1.66 \%$ \\
\hline & 1.74 & $44.49 \%$ & 2.737 & 0.57299 & 0.561 & $0.60 \%$ \\
\hline & 1.74 & $44.49 \%$ & 2.756 & 0.58391 & 0.5613 & $1.13 \%$ \\
\hline & 1.6 & $70.46 \%$ & 2.729 & 0.70562 & 0.6912 & $0.72 \%$ \\
\hline \multirow{6}{*}{$\begin{array}{l}\text { Fine } 0.15-0.25 \\
\text { Skeleton } 1-2\end{array}$} & 1.56 & $73.38 \%$ & 2.738 & 0.75513 & 0.7154 & $1.99 \%$ \\
\hline & 1.73 & $52.56 \%$ & 2.718 & 0.5711 & 0.5911 & $-1.00 \%$ \\
\hline & 1.78 & $44.73 \%$ & 2.764 & 0.55281 & 0.5621 & $-0.46 \%$ \\
\hline & 1.75 & $47.82 \%$ & 2.817 & 0.60971 & 0.5737 & $1.80 \%$ \\
\hline & 1.74 & $50.39 \%$ & 2.761 & 0.58678 & 0.5836 & $0.16 \%$ \\
\hline & 1.6 & $69.68 \%$ & 2.772 & 0.7325 & 0.694 & $1.93 \%$ \\
\hline
\end{tabular}

grain content, and the minimum void ratio, identified in the Section 3, in combination with the guarantee rate $\alpha$, the conditional probability function (Equation (13)) is established. The optimal guarantee rate $\alpha_{0}$ for predicting the minimum void ratio is 0.485 verified by 56 sets of data in Table 2 . The specific gravity and fine grain content of the other 16 sets of data tested in the laboratory are combined with the optimal guarantee rate $\alpha_{0}$ into Equation (13) to predict the estimation' $e_{\min }$ of the minimum void ratio under the optimal guarantee rate $\alpha_{0}$, the results of which are given in Table 8 (a negative value indicates that the predicted value is greater than the actual value, and a positive value indicates that the predicted value is less than the actual value). The maximum error is $1.99 \%$, and the minimum error is $0.16 \%$. This error is within the acceptable range in practical engineering. In general, the data predicted by the joint probability distribution model based on the Gumbel-Hougard copula are more realistic.

\section{Conclusions}

In this paper, the tailings of a tungsten mine in southern Shaanxi were taken as the research object. The correlation between fine particle size content, specific gravity, and the minimum void ratio was analyzed, and the optimal marginal distribution of the minimum void ratio and related parameters was determined. The joint distribution function between the minimum void ratio and related parameters was constructed, the joint probability distribution model is established by combining the joint distribution function and guarantee rate, and the value of the minimum void ratio was predicted by the joint probability distribution model. The conclusions are as follows:

(1) There was a strong positive correlation between the fine particle content and minimum pore ratio, and a strong positive correlation between the specific gravity and minimum pore ratio. The optimal edge distribution of the fine particle content and specific gravity was a truncated normal distribution, and the optimal edge distribution function of the minimum void ratio was a logarithmic normal distribution

(2) The optimal Archimedean copula function fitting fine grain content, specific gravity, and the minimum void ratio was a Gumbel-Hougard copula function. The optimal fitting guarantee rate of the GumbelHougard copula function was 0.485 ; the joint probability distribution model established by combining the guarantee rate $\alpha$ and Gumbel-Hougard copula function could effectively predict the minimum pore ratio when the fine particle content and specific gravity were known, and the error meets the accuracy requirements of practical applications.

\section{Data Availability}

All data and models generated or used during the study appear in the submitted article.

\section{Conflicts of Interest}

The authors declare that they have no conflicts of interest.

\section{Acknowledgments}

This work was supported by the National Natural Science Foundation of China (No. 41907255, 41602359), the Natural Science Basic Research Plan in Shaanxi Province of China (No. 2017JQ4019), and Key Laboratory of the Northern Qinghai-Tibet Plateau Geological Processes and Mineral Resources (No. 2019-KZ-01).

\section{References}

[1] S. W. Wu, C. H. Yang, C. Zhang, H. J. Mao, Y. Q. Du, and X. Z. Zhang, "Particle size distribution of fine-grained tailings based on Weibull distribution," Journal of Chongqing University, vol. 39, no. 3, pp. 1-12, 2016. 
[2] J. Q. Ma, H. Peng, S. B. Li, Z. Duan, X. S. Zhang, and D. H. Ma, "Exploring the occurrence of clogging in highly permeable coarse soils of dam foundations," Advances in Civil Engineering, vol. 2020, Article ID 8868052, 16 pages, 2020.

[3] C. Zhang, C. K. Ma, C. H. Yang, Q. L. Chen, and Z. K. Pan, "Effects of particle diameter on shear strength of tailings and stability of tailings dams," Chinese Journal of Geotechnical Engineering, vol. 41, Supplement 1, pp. 145-148, 2019.

[4] Q. G. Zhang, Y. M. Wang, G. Z. Li et al., "Simulation of the mesomechanics mechanism of the tailings dam's deformation with particle flow code," Journal of Chongqing University, vol. 38, no. 3, pp. 71-79, 2015.

[5] A. Sklar, Fonctions de repartition an dimensions etleurs marges vol. 8, Publications de l' Institut de Statistique de l' Universite de Paris, 1959.

[6] R. B. Nelsen, An Introduction to Copulas, Springer, New York, NY, 2006.

[7] X. S. Tang, D. Q. Li, Z. J. Cao, and K. K. Phoon, "Impact of sample size on geotechnical probabilistic model identification," Computers and Geotechnics, vol. 87, no. 2, pp. 229240, 2017.

[8] X. S. Tang, D. Q. Li, C. B. Zhou, and K. K. Phoon, "Modeling dependence between shear strength parameters using copulas and its effect on slope reliability," Chinese Journal of Geotechnical Engineering, vol. 34, no. 12, pp. 2284-2291, 2012.

[9] L. Zhang, D. Q. Li, X. S. Tang, Z. J. Cao, and K. K. Phoon, "Bayesian model comparison and characterization of bivariate distribution for shear strength parameters of soil," Computers and Geotechnics, vol. 95, no. 3, pp. 110-118, 2018.

[10] L. Zhang, X. S. Tang, and D. Q. Li, "Bivariate distribution model of soil shear strength parameter using copula," Journal of Civil Engineering and Management, vol. 30, no. 2, pp. 1117+36, 2013.

[11] X. L. Zhou, G. Zhang, S. H. Hu, J. Z. Li, and J. Ji, “Optimal estimation of shear strength parameters based on copula theory coupling information diffusion technique," Advances in Civil Engineering, vol. 2019, Article ID 8738969, 18 pages, 2019.

[12] D. Huang, C. Yang, B. Zeng, G. Fu, and X. F. Xu, "A copulabased method for estimating shear strength parameters of rock mass," Mathematical Problems in Engineering, vol. 2014, no. 10, Article ID 693062, pp. 1-1111, 2014.

[13] X. J. Kong, L. F. Song, B. Xu, and D. G. Zou, "Correlation and distribution model for nonlinear strength parameters of rockfill based on copula function," Chinese Journal of Geotechnical Engineering, vol. 42, no. 5, pp. 797-807, 2020.

[14] S. S. Li, D. Y. Li, and Y. F. Gao, "Determination of maximum and minimum void ratios of sands and their influence factors," Chinese Journal of Geotechnical Engineering, vol. 40, no. 3, pp. 554-561, 2018.

[15] J. Kim, T. Kawai, and M. Kazama, "Minimum void ratio characteristic of soils containing non-plastic fines," Soils and Foundations, vol. 59, no. 6, pp. 1772-1786, 2019.

[16] Z. Z. Wu and G. D. Mei, "Statistical analysis of tailings pond accidents and cause analysis of dam failure," China Safety Science Journal, vol. 24, no. 9, pp. 70-76, 2014.

[17] TCGETE GB50547-2010, Technical code for geotechnical engineering of tailings embankment, Ministry of Housing and Urban-Rural Development of the People's Republic of China, General Administration of Quality Supervision, Inspection and Quarantine of the People's Republic of China, China Planning Press, Beijing, 2010.
[18] X. D. Zhang, H. Cai, Y. Q. Wei, Z. T. Zhang, J. H. Liang, and J. $\mathrm{Hu}$, "Characterization of the seismic behavior of tailings reservoir founded on soft soil using dynamic centrifuge tests," Rock and Soil Mechanics, vol. 41, no. 4, pp. 1287-1304, 2020.

[19] L. Qiao, C. L. Qu, and M. Cui, "Effect of fines content on engineering characteristics of tailings," Rock and Soil Mechanics, vol. 36, no. 4, pp. 923-9945, 2015.

[20] L. E. Vallejo, "Interpretation of the limits in shear strength in binary granular mixtures," NRC Research Press Ottawa, Canada, vol. 38, no. 5, pp. 1097-1104, 2001.

[21] S. Thevanayagam and G. R. Martin, "Liquefaction in silty soils-screening and remediation issues," Soil Dynamics and Earthquake Engineering, vol. 22, no. 9-12, pp. 1035-1042, 2002.

[22] SETM GB/T 50123-2019, Standard for geotechnical testing method, Ministry of Water Resources of China, China Planning Press, Beijing, 2019.

[23] S. Kotz and D. Drouet, Correlation and Dependence, World Scientific, 2001.

[24] A. D. Aczel and J. Sounderpandian, Complete business statistics, Irwin/McGraw Hill, Boston, MA, 1999.

[25] C. Yang, D. Huang, and Y. X. Zhang, "Multivariable correlation rock quality index $\mathrm{Q}$ system value, wave velocity and deformation modulus based on copula theory," Chinese Journal of Rock Mechanics and Engineering, vol. 33, no. 3, pp. 507-513, 2014.

[26] J. T. Cheng, C. X. Yu, K. J. Wan, and Q. Cai, "Probability distribution model and value range research on physical and mechanical parameters of tailing silt soils," Yangtze River, vol. 45, no. 9, pp. 90-101, 2014.

[27] X. S. Tang, D. Q. Li, C. B. Zhou, and K. K. Phoon, "Effect of sample size on identification of a joint probability distribution underlying correlated geotechnical parameters," Engineering Mechanics, vol. 32, no. 2, pp. 1-11, 2015.

[28] L. F. Song, X. J. Kong, B. Xu, and R. Pang, "Reliability analysis of 3D rockfill dam slope stability based on copula function," Journal of Dalian University of Technology, vol. 61, no. 1, pp. 92-103, 2021.

[29] H. Akaike, "A new look at the statistical model identification," IEEE transactions on automatic control, vol. 19, no. 6, pp. 716723, 1974.

[30] G. Schwarz, "Estimating the dimension of a model," The Annals of Statistics, vol. 6, no. 2, pp. 461-464, 1978.

[31] Z. Q. Zhang, Q. B. Wu, G. L. Jiang, S. R. Gao, J. Chen, and Y. Z. Liu, "Changes in the permafrost temperatures from 2003 to 2015 in the Qinghai-Tibet Plateau," Cold Regions Science and Technology, vol. 169, no. 102904, 2020.

[32] Z. Q. Zhang, Q. B. Wu, M. T. Hou, B. W. Tai, and Y. K. An, "Permafrost change in Northeast China in the 1950s-2010s," Advances in Climate Change Research, vol. 12, no. 1, pp. 1828, 2021.

[33] S. B. Li, H. Liang, H. Li, J. Q. Ma, and B. Lin, "Minimum void ratio model establishing of tailings and determination of optimal void ratio," Geofluids, Article ID 8619121, 2021, vol. Thermal-Hydro-Mechanical Interactions in Saturated and Unsaturated Soils.

[34] X. D. Zhang, E. C. Zhai, Y. J. Wu, D. A. Sun, and Y. T. Lu, "Theoretical and numerical analyses on hydro-thermal-saltmechanical interaction of unsaturated salinized soil subjected to typical unidirectional freezing process," International Journal of Geomechanics, vol. 21, no. 7, article 04021104, 2021. 
[35] C. Yang, D. Huang, Y. X. Zhang, and J. H. Wu, "Estimation shear strength parameters of rock mass based on copula theory," Chinese Journal of Rock Mechanics and Engineering, vol. 32, no. 12, pp. 2463-2470, 2013.

[36] D. Huang, B. Zeng, and Q. L. Wang, "Study on probabilistic relation between permeability coefficient and void ratio and grain composition of coarse grained soils using copula theory," Journal of Hydraulic Engineering, vol. 46, no. 8, pp. 900-907, 2015. 